\title{
Optimum tilt and azimuth for solar collectors in South Africa using measured data
}

\author{
W.G. Le Roux \\ Department of Mechanical and Aeronautical Engineering, \\ University of Pretoria, South Africa \\ Address: Private Bag X20, Hatfield, Pretoria 0028, South Africa \\ E-mail: willem.leroux@up.ac.za
}

\begin{abstract}
The solar resource in South Africa is among the best in the world. South Africa has seen an increase in local and international investment in solar power. The optimum angles at which a solar collector should be mounted are often debated. Similar publications on this topic often rely on mathematical models of solar resource rather than measured data. Measured data is preferred since the effects of pollution and weather are included. In this work, recently measured data from nine measuring stations in the Southern African Universities Radiometric Network (SAURAN) equipped with pyranometers and pyrheliometers are considered. The data is used to calculate the annual solar insolation on fixed collectors at all possible installation angles. SolTrace, a ray-tracing software, is used for validation. Relative to a horizontally-fixed collector, the annual solar insolation is $10 \%$ more for optimally-fixed collectors and $45 \%$ more for solar-tracking collectors. The effects of tilt and azimuth angles are presented on contour plots, which are convenient for cost analysis and the determination of the annual insolation on building surfaces. The optimum azimuth angle is a function of the longitude angle minus the absolute latitude angle, which suggests that frontal and convective precipitation effects influence the optimum azimuth angle.
\end{abstract}

\section{Keywords}

solar; azimuth; tilt; optimum; collector; South Africa 


\section{Nomenclature}

C

D

H

I

S

SOF

$T$

$x$

$X$

y

Y

$z$

Z

Greek symbols

$\alpha$

$\beta$

$\delta$

$\varepsilon$

$\Theta$

$\rho$

$\sigma$

$\phi$

$\Psi$

$\omega$

Subscripts

calc

$e$

$G S A$
Constant

Average diffuse horizontal irradiance $\left[\mathrm{W} / \mathrm{m}^{2}\right]$

Average global horizontal irradiance $\left[\mathrm{W} / \mathrm{m}^{2}\right]$

Average direct normal irradiance $\left[\mathrm{W} / \mathrm{m}^{2}\right]$

Annual solar insolation $\left[\mathrm{kWh} / \mathrm{m}^{2}\right]$

Surface orientation factor [-]

Average solar irradiance on collector surface $\left[\mathrm{W} / \mathrm{m}^{2}\right]$

Position in the $x$-axis [m]

Position of the sun in the $x$-axis [m]

Position in the $y$-axis [m]

Position of the sun in the $y$-axis [m]

Position in the $z$-axis [m]

Position of the sun in the $z$-axis [m]

Elevation angle of the sun

Tilt angle of collector

Declination angle

Percentage error

Azimuth angle of the sun

Reflectivity of surface

Longitude angle minus absolute latitude angle

Latitude angle

Azimuth angle of collector

Hour angle

As calculated

Extra-terrestrial

According to GeoSun Africa 


$\begin{array}{ll}H & \text { Using global horizontal irradiance } \\ I & \text { Using direct normal irradiance } \\ \max & \text { Maximum } \\ \text { opt } & \text { Optimum } \\ \text { tilt } & \text { For a fixed and tilted surface } \\ \text { track } & \text { For a solar-tracking surface }\end{array}$

Abbreviations

DHI Diffuse Horizontal Irradiance

DNI Direct Normal Irradiance

GHI Global Horizontal Irradiance

GIZ German Society for International Cooperation

GSA GeoSun Africa

NREL National Renewable Energy Laboratory

SAURAN Southern African Universities Radiometric Network

SAWS South African Weather Service

SOF Surface Orientation Factor 


\section{Introduction}

South Africa has one of the best solar resources in the world. It is blessed with much space and plenty of solar hours. Large-scale grid-connected solar power plants are becoming more popular and small-scale solar collection using photovoltaic panels and solar water heaters is also a growing tendency in South Africa. The sun's power and position is a function of time and day and therefore, to capture the most power from the sun throughout a typical year, a solar collector should be placed on a two-axis solar tracking system so that it faces the sun at all times. However, two-axis solar tracking systems can be expensive and should be priced correctly to justify the cost. For crystalline silicon (c-Si) PV modules, the annual solar insolation obtained with a two-axis solar tracking system in South Africa is only about 3\% higher than the annual solar insolation obtained with a one-axis solar tracking system [1]. This makes one-axis solar tracking systems more attractive in terms of cost.

Another solar-collection approach is to fix the solar collector at a certain tilt angle and azimuth rotation angle for the full duration of its lifetime. These angles can be chosen to obtain either maximum annual solar insolation or to obtain maximum daily solar insolation throughout the year [2]. The fixed-collector approach is often considered instead of a solar tracking system, which is associated with extra cost. Many studies have been done to determine the optimum fixed positions of solar collectors for locations all over the world [3]. Results are often based on mathematical models of the solar resource, measured solar data or both.

Optimum fixed-collector positions based on mathematical models of solar resource are available for countries such as Lesotho [4], Cyprus [5], Egypt [6], Brunei Darussalam [7], China [8], Iran [9], the western Himalayas [10], India [11] and Malaysia [12]. Estimation and optimization of the incident solar radiation on tilted surfaces can also be determined using different empirical models [13-14]. A solar radiation data manual for flat-plate and concentrating collectors was made available for the United States of America by the National Renewable Energy Laboratory [15]. Both mathematical models of solar resource and measured solar data were used to calculate solar insolation expected on tilted surfaces at various locations.

Optimum fixed-collector positions based on measured solar data are available for locations such as Bet-Dagan, Israel [16], Surabaya, Indonesia [17] and Spain [18]. Optimum fixedcollector positions based on data from photovoltaic panels at different angles are available for locations such as Hannover, Germany [19] and Tehran, Iran [20]. Results based on measured 
solar data include the effects of pollution and weather of the specific location. Solar data from regularly calibrated ground measurement stations are considered to be the most accurate [2] and, therefore, daily measured data at minute or hourly intervals is preferred.

Studies have been done in South Africa to determine the optimum fixed position of solar collectors, but these studies do have some limitations. Similar to other locations in the world, results were based on mathematical models of solar resource, measured solar data or both. Suri et al. [1] presented a method for estimating the annual energy output from fixed and tracking solar collectors in South Africa using numerical models of solar resource. Suri et al. [1], however, did not investigate the effect of azimuth rotation and assumed that the collector should face north. Optimum tilt angles for photovoltaic panels in the Vaal Triangle of South Africa have been determined experimentally, although only for the winter months, using photovoltaic panels at different orientations [21]. Matshoge and Sebitosi [22] also proposed optimum tilt and azimuth rotation angles of specifically solar photovoltaic panels in South Africa with the use of Meteonorm software. This study took into consideration factors such as wind speed and wind direction to cool the solar cells and is thus not relevant to all solar collector technologies. In 1975, Kern and Harris [23] investigated the optimum collector-tilt angle as a function of latitude, weather data and character of the energy demand in South Africa for Pretoria, Cape Town and Durban. Data of mean daily solar radiation on a horizontal surface from the Weather Bureau was used, which dated back to 1954 [23]. Bekker [2] also found optimum collector angles for various locations in South Africa using normalised measured data from the South African Weather Service (SAWS). The SAWS was the main source of ground measurement irradiance data in South Africa during the past few decades [2]. These ground measurements only included global and diffuse irradiance on horizontal surfaces. More recently, however, the measuring equipment has not been calibrated as often as the manufacturers recommended, making this data less accurate [2]. The effects of tilt angle and azimuth rotation angle on the annual solar insolation of a collector can be conveniently presented with the use of a contour plot of surface orientation factor. The surface orientation factor is defined as the ratio of the annual solar insolation on a specifically orientated surface to the annual solar insolation on an optimally orientated surface [24]. Christensen and Barker [24] presented such contour plots for different locations in the United States of America using solar data based on mathematical models. Ng et al. [12] presented similar contour plots based on mathematical models for Malaysia. Li and Lam [25] also presented contour plots for Hong Kong, but these were based on measured solar data. 
Contour plots of surface orientation factor, showing the optimum fixed orientation of solar collectors in South Africa using accurate measured data, are not available in the current literature. In this work, recently measured data from nine measuring stations in the Southern African Universities Radiometric Network (SAURAN) equipped with pyranometers and pyrheliometers are considered. The data is used to calculate the annual solar insolation on fixed collectors at all possible installation angles. The paper presents the optimum tilt and azimuth orientation angles and contour plots of surface orientation factor for these locations. In the next section, the methodology of data collection, data processing, validation and determining the optimum angles are discussed, where after the optimum tilt and azimuth rotation angles and contour plots are presented.

\section{Methodology}

\subsection{Solar measurement}

In South Africa, an initiative of county-wide solar measurement has started in recent years through the SAURAN. Most of the ground stations in the network use a SOLYS 2 solar tracking system with Kipp \& Zonen CMP11 pyranometers for GHI and DHI measurements and a CHP1 pyrheliometer for DNI measurements [26,27]. The instruments are regularly cleaned and calibrated. Solar measurements from nine different locations across South Africa are considered from the SAURAN [26]. These locations are Bloemfontein, Durban (two locations), Graaff-Reinet, Pretoria, the Richtersveld, Stellenbosch, Van Rhynsdorp and Vryheid, as shown in Fig. 1. Fig. 2 shows a picture of the measuring station in Pretoria.

The coordinates and important information of each location are presented in Table 1 [26]. It should be noted that most of the stations are only a few years old. The sensors are still well calibrated and the tracking systems are accurate. Stellenbosch is the oldest station and provides the most data. Other stations included in the SAURAN, such as Port-Elizabeth, Sutherland, Gaborone, Venda and Reunion Island, could not be included in the study due to unreliable or insufficient data at the time of data collection. The past few years' hour-average and minute-average solar measurements at each station were obtained. According to SAURAN [26], all averages are calculated for the period immediately preceding the timestamped value. 


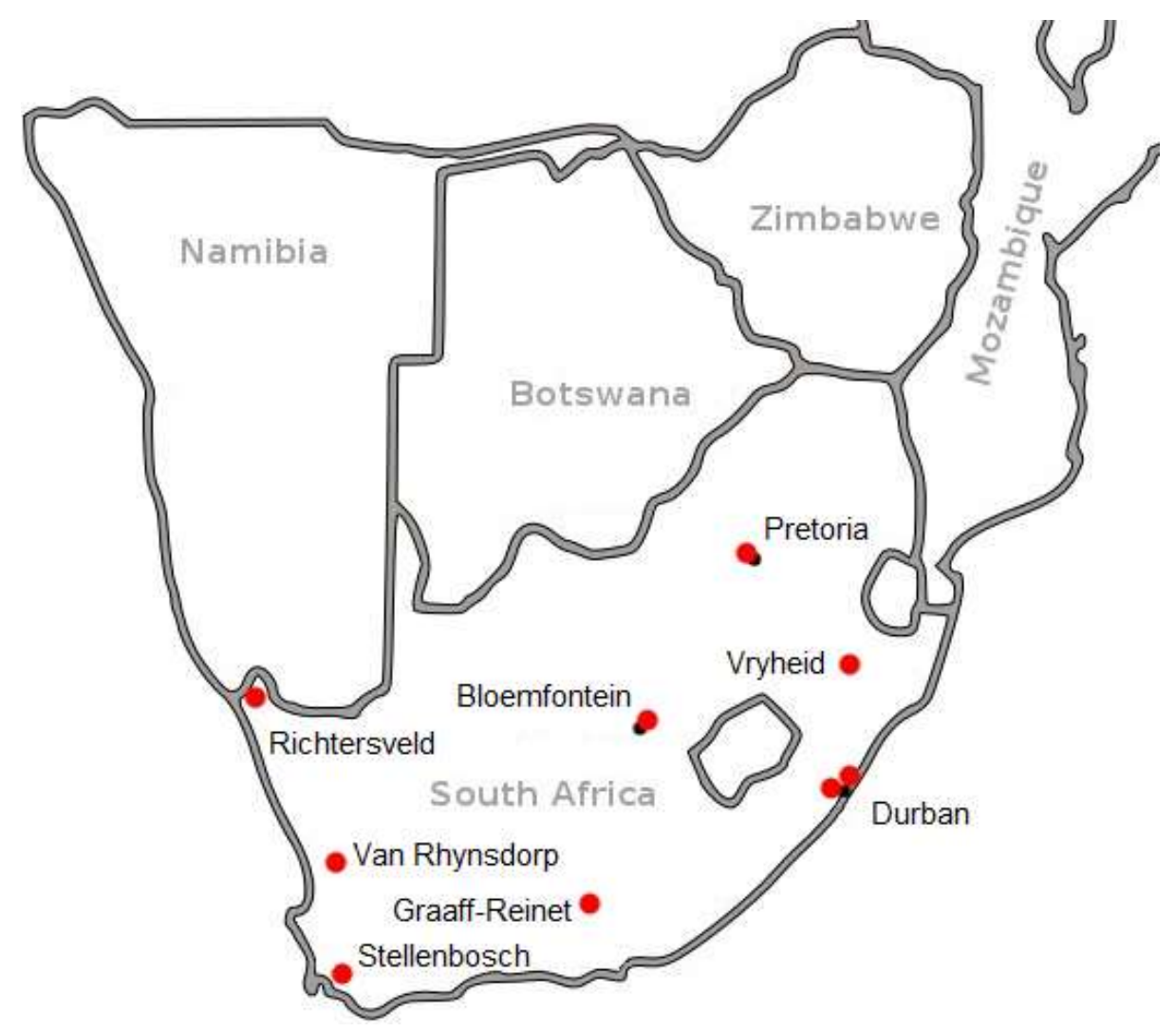

Fig. 1. Map of South Africa showing the locations of the solar measuring stations [26].

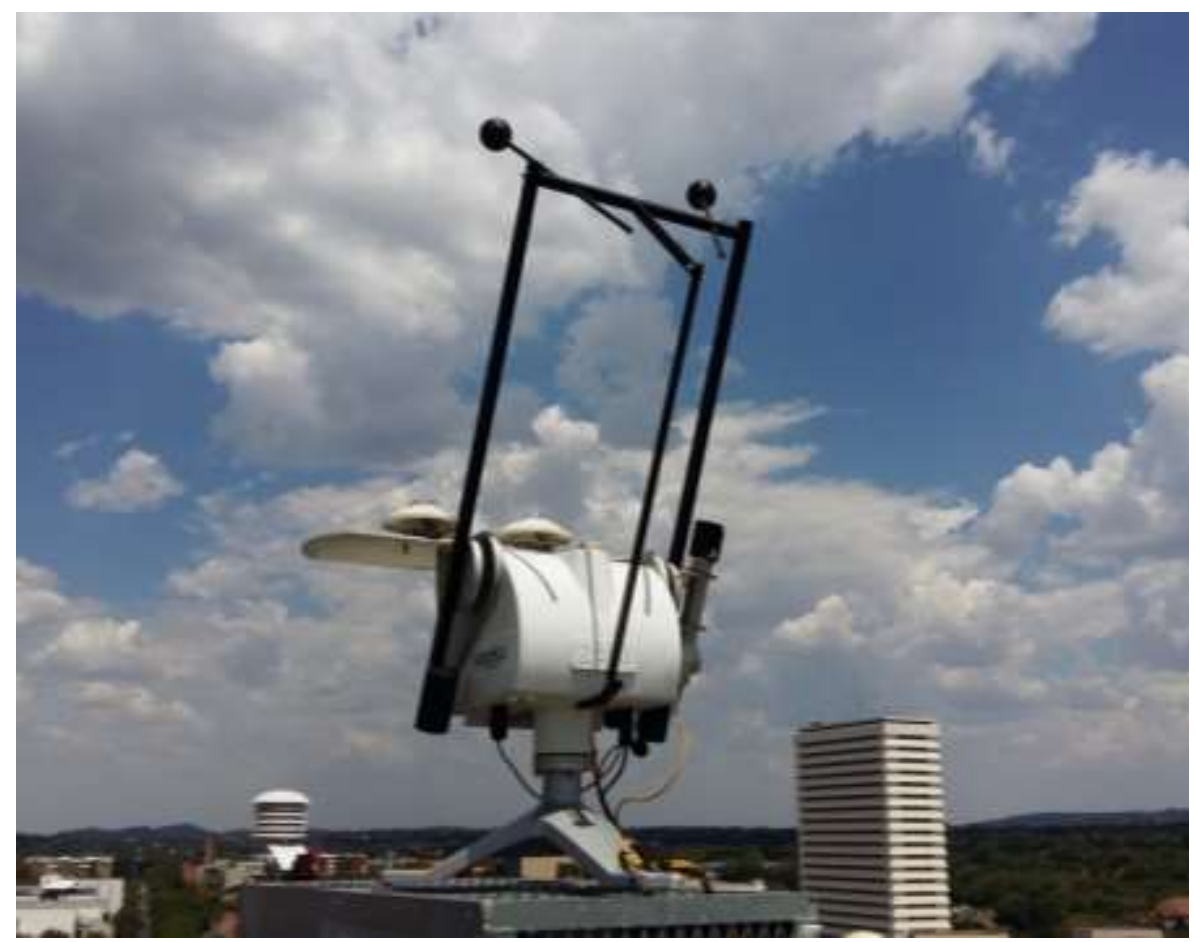

Fig. 2. The SOLYS 2 solar tracking system with Kipp \& Zonen CMP11 pyranometers and CHP1 pyrheliometer. 


\subsection{Data processing}

The minute-average and hour-average solar DNI, GHI and DHI data from each location were analysed and processed carefully in order for the hour-average data to be used for the purposes of this paper. The minute-average data was only used for additional quality-control purposes. For each station, the data collected since the installation date (see Table 1) and up to 23 February 2016 were considered.

\section{Table 1}

Details of the stations in the SAURAN [26].

\begin{tabular}{|c|c|c|c|c|c|}
\hline Location & Latitude $\left(^{0}\right)$ & Longitude $\left(^{0}\right)$ & $\begin{array}{l}\text { Elevation } \\
\text { (m) }\end{array}$ & Description & $\begin{array}{l}\text { Installation } \\
\text { date }\end{array}$ \\
\hline Bloemfontein & -29.11074 & 26.18503 & 1491 & $\begin{array}{l}\text { University of } \\
\text { the Free State }\end{array}$ & $\begin{array}{l}12 \text { October } \\
2013\end{array}$ \\
\hline Durban & -29.816942 & 30.944917 & 200 & $\begin{array}{l}\text { University of } \\
\text { KwaZulu- } \\
\text { Natal: } \\
\text { Westville }\end{array}$ & 9 April 2013 \\
\hline Durban & -29.87098 & 30.97695 & 150 & $\begin{array}{l}\text { University of } \\
\text { KwaZulu- } \\
\text { Natal: Howard }\end{array}$ & April 2012 \\
\hline $\begin{array}{l}\text { Graaff- } \\
\text { Reinet }\end{array}$ & -32.48547 & 24.58582 & 660 & $\begin{array}{l} \pm 26 \mathrm{~km} \text { south } \\
\text { of town }\end{array}$ & $\begin{array}{l}29 \text { November } \\
2013\end{array}$ \\
\hline Pretoria & -25.74611 & 28.18805 & 1410 & $\begin{array}{l}\text { University of } \\
\text { Pretoria }\end{array}$ & $\begin{array}{l}7 \text { September } \\
2013\end{array}$ \\
\hline Richtersveld & -28.56084 & 16.76146 & 141 & $\begin{array}{l} \pm 30 \mathrm{~km} \text { east of } \\
\text { Alexander Bay }\end{array}$ & 4 April 2014 \\
\hline Stellenbosch & -33.9281 & 18.8654 & 119 & $\begin{array}{l}\text { University of } \\
\text { Stellenbosch }\end{array}$ & 24 May 2010 \\
\hline $\begin{array}{l}\text { Van } \\
\text { Rhynsdorp }\end{array}$ & -31.61748 & 18.73834 & 130 & $\begin{array}{l} \pm 1.5 \mathrm{~km} \text { south } \\
\text { of town }\end{array}$ & $\begin{array}{l}15 \text { November } \\
2013\end{array}$ \\
\hline Vryheid & -27.82817 & 30.49996 & 1277 & $\begin{array}{l} \pm 40 \mathrm{~km} \text { west } \\
\text { of town }\end{array}$ & $\begin{array}{l}12 \text { September } \\
2013\end{array}$ \\
\hline
\end{tabular}


Quality control of the data included the elimination of non-physical values and the elimination of incorrect data due to tracking errors, maintenance, power failures and lightning strikes. Data where $D>1.1 H, H>1.2 H_{e}, D>0.8 H_{e}$ or $H-D>H_{e}$ were identified as potential non-physical values [27]. Possible solar-tracker malfunction was found by flagging all minute data where $|H-D|<5 \mathrm{~W} / \mathrm{m}^{2}, I<1.5 \mathrm{~W} / \mathrm{m}^{2}$ and $H>600 \mathrm{~W} / \mathrm{m}^{2}$ [27]. These quality control flags are similar to those employed by [28].

For each location, hour-average GHI, DNI and DHI were considered for calculations. The hour-average data was split up into different years and sorted firstly according to the hour of the day and then according to the day of the year. Since more than one year's data was available for each location, the average data of GHI, DNI and DHI for each hour of the year could be determined and were used in the analysis.

Furthermore, for each location, the average hourly position of the sun was found for each day of the year according to [29] which uses the Michalsky algorithm [30]. The SOLYS 2 also uses the Michalsky algorithm to track the sun [31]. The Michalsky algorithm is used to determine the elevation angle, $\alpha$, and azimuth angle, $\Theta$, of the sun as shown in Eq. (1) and Eq. (2) where $\phi$ is the latitude angle of the site. According to [30], the declination angle, $\delta$, is a function of the obliquity of the ecliptic and the ecliptic longitude which is determined from the Julian date, while the hour angle, $\omega$, is a function of the Julian date, universal time and east longitude [30]. Since hour-average solar data is used, the sun's position on the half hour had to be obtained for the analysis. For Durban, data from two measuring stations were considered and therefore the sun path at a position exactly between the two stations with the average decimal coordinates of $-29.843866^{\circ}$ (latitude), $30.960633^{\circ}$ (longitude) were used in the analysis.

$\sin \alpha=\sin \delta \sin \phi+\cos \delta \cos \phi \cos \omega$

$\sin \Theta=-\cos \delta \sin \omega / \cos \alpha$

With the average global horizontal irradiance, $H\left(\mathrm{~W} / \mathrm{m}^{2}\right)$, available for each of the 8760 hours of the year for each location, the annual insolation on a horizontal collector, $S_{H}\left(\mathrm{kWh} / \mathrm{m}^{2}\right)$, could be determined as shown in Eq. (3). With the average direct normal irradiance, $I\left(\mathrm{~W} / \mathrm{m}^{2}\right)$, average diffuse horizontal irradiance, $D\left(\mathrm{~W} / \mathrm{m}^{2}\right)$, and the average 
elevation angle of the sun, $\alpha\left({ }^{0}\right)$, available for each hour of the year for each location, the hourly global horizontal irradiance, $H_{\text {calc }}\left(\mathrm{W} / \mathrm{m}^{2}\right)$, was also calculated using Eq. (4) $[27,32]$ and the annual global horizontal insolation, $S_{H, c a l c}\left(\mathrm{kWh} / \mathrm{m}^{2}\right)$, calculated as shown in Eq. (5). The accuracy of the measured results is based on the percentage error, $\varepsilon$, as shown in Eq. (6).

$$
\begin{aligned}
& S_{H}=\sum_{i=1}^{8760} H_{i} \\
& H_{\text {calc }}=I \sin \alpha+D \\
& S_{H, \text { calc }}=\sum_{i=1}^{8760} H_{\text {calc }, i} \\
& \varepsilon=\left|\frac{S_{H}-S_{H, \text { calc }}}{S_{H}}\right|
\end{aligned}
$$

For a solar collector positioned on a two-axis tracking system, so that the normal of the collector aims directly towards the sun, the average hourly solar irradiance, $T_{\text {track }}\left(\mathrm{W} / \mathrm{m}^{2}\right)$, on the solar-tracking collector surface can be determined with Eq. (7) [4-6,32]. Equation (7) shows the effects of $I, D$ and the reflected $H$ from the ground, where $\rho$ is the reflectivity.

$$
T_{\text {track }}=I+D[1+\cos (90-\alpha)] / 2+\rho H[1-\cos (90-\alpha)] / 2
$$

According to [24], increased ground reflectance due to snow can shift the optimum tilt angle approximately $2^{0}$ higher. South Africa is a dry country and does not get snow very often. In Eq. (7), the ground reflection, $\rho$, was thus chosen as 0.2 , which is typical for grass or sand $[11,24,32]$. The isotropic model by Liu and Jordan, cited by [9], was used to determine the diffuse component of the solar irradiance on a tilted surface as shown in Eq. (7). More accurate ways to determine the diffuse component of solar irradiance on tilted surfaces are available [2,3,9,13,18,33,34]; however, the isotropic model is simple and displays intermediary performance compared to other models [35]. 


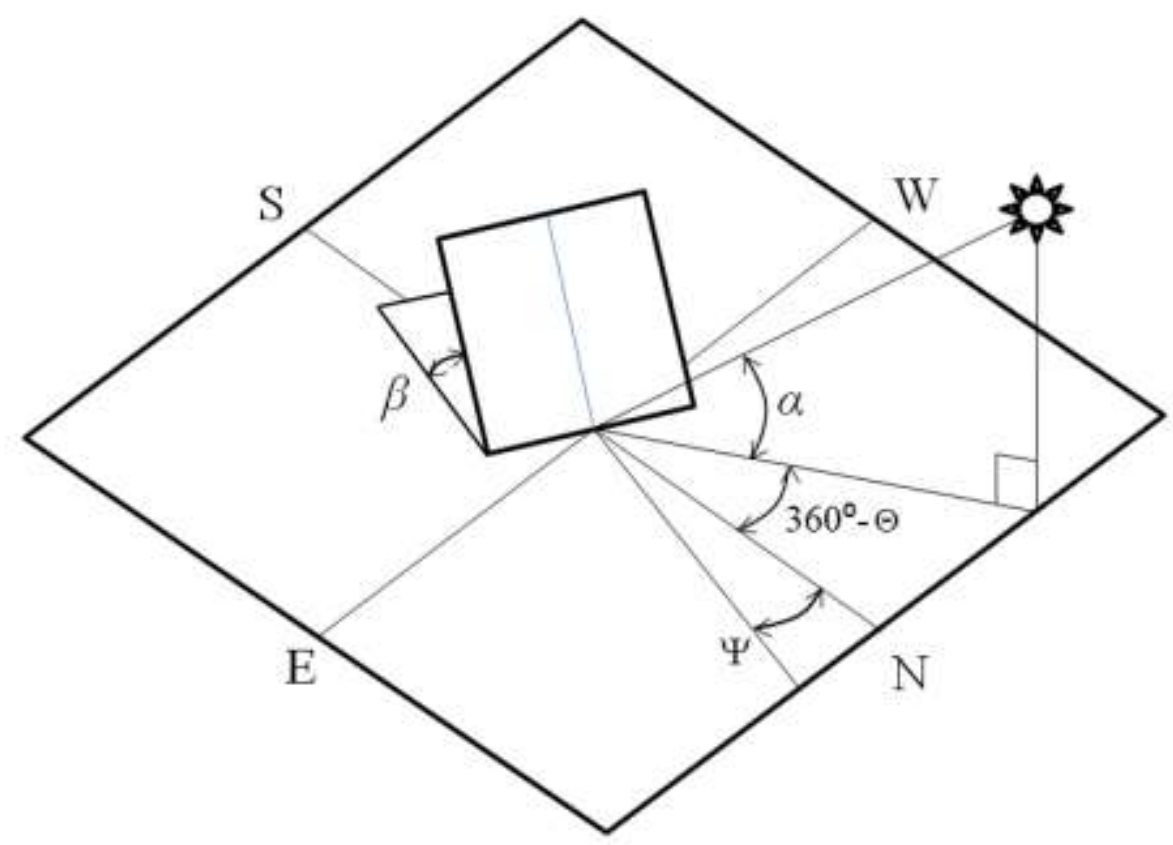

Fig. 3. Definition of the solar angles and collector angles.

The hour-average solar irradiance, $T_{\text {tilt }}\left(\mathrm{W} / \mathrm{m}^{2}\right)$, available on a fixed-collector surface (Fig. 3) can be determined similarly as shown in Eq. (8), by adding the components of DNI, DHI and reflected GHI from the ground [11,18,34],

$T_{\text {tilt }}=C I+D(1+\cos \beta) / 2+\rho H(1-\cos \beta) / 2$

where, according to $[6,25,32,34,36]$,

$C=\cos \alpha \sin \beta \cos (\Psi-\Theta)+\sin \alpha \cos \beta$

Note that $\alpha$ is defined as the elevation angle of the sun, $\beta$ as the tilt angle of the collector, $\Theta$ as the azimuth angle of the sun and $\Psi$ as the azimuth angle of the collector. It is also assumed that, if $C<0$ (when the collector is cast in its own shade), the available solar irradiance on the fixed-collector surface can be determined with Eq. (10).

$T_{\text {tilt }}=D(1+\cos \beta) / 2+\rho D(1-\cos \beta) / 2$ 
Using the equations above, the annual solar insolation, $S_{\text {track }}\left(\mathrm{kWh} / \mathrm{m}^{2}\right)$, can be determined for a solar-tracking collector as shown in Eq. (11). Similarly, the annual solar insolation, $S_{\text {tilt }}\left(\mathrm{kWh} / \mathrm{m}^{2}\right)$, can be determined for a collector surface fixed at any tilt angle and azimuth angle as shown in Eq. (12). As shown in Eq. (13), the surface orientation factor, SOF, is defined as the annual solar insolation of a solar collector with a specific tilt angle and azimuth angle relative to the annual solar insolation of a collector which is fixed at the optimum tilt angle and azimuth angle.

$$
\begin{aligned}
& S_{\text {track }}=\sum_{i=1}^{8760} T_{\text {track }, i} \\
& S_{\text {tilt }}=\sum_{i=1}^{8760} T_{\text {tilt }, i}
\end{aligned}
$$

$$
S O F=S_{t i l t} / S_{\text {tilt, } \max }
$$

\subsection{Validation}

SolTrace [37], a ray-tracing software developed by the National Renewable Energy Laboratory (NREL), was used to validate the analysis and was also used for visual inspection. In SolTrace, the elevation angle of the sun is defined as shown in Eq. (14) where $X, Y$ and $Z$ defines the position of the sun. In Fig. 3, the positive $x$-axis points towards the East and the positive $y$-axis points towards the North. The azimuth angle of the sun is defined as shown in Eq. (15).

$$
\begin{aligned}
& \tan \alpha=Z / \sqrt{X^{2}+Y^{2}} \\
& \tan \left(360^{\circ}-\Theta\right)=X / Y
\end{aligned}
$$

Similarly, the tilt angle of the collector in SolTrace is defined with Eq. (16) using the collector aim-points, $x, y$ and $z$. The azimuth angle of the collector is defined in Eq. (17). A zrotation is also implemented after positioning the collector towards the aim-point. 
$\tan \left(90^{\circ}-\beta\right)=z / \sqrt{x^{2}+y^{2}}$

$\tan \Psi=x / y$

As an example of the validation process, a $1 \mathrm{mx} 1 \mathrm{~m}$ collector in Pretoria at 10:30 on 1 January with $\alpha=66.96^{\circ}, \Theta=87.88^{\circ}, \beta=12.60^{\circ}$ and $\Psi=-26.57^{\circ}$ is considered. According to Eq. (9), $C=0.8627$ for the collector. $C$ is also calculated with SolTrace as validation as shown in Fig. 4. The sun's position is calculated to be at $X=107.8, Y=4$, and $Z=253.6$ according to Eq. (14) and Eq. (15). The collector aim-points are defined as $x=-5, y=10$ and $z=50$ according to Eq. (16) and Eq. (17). SolTrace shows that for an irradiance of $1000 \mathrm{~W} / \mathrm{m}^{2}$ available from the sun's rays, the irradiance collected on the $1 \mathrm{~m} \times 1 \mathrm{~m}$ surface is $862.8 \mathrm{~W}$. Thus $C=0.8628$ according to SolTrace, which validates the equations used in the analysis. Furthermore, SolTrace helps with the visual inspection of the collector and the direction of the sun rays as shown in Fig. 5. Fig. 5c shows that the sun's rays are coming in at an angle of $2.12^{\circ}$ north of east and that the collector is positioned at an azimuth angle of $26.57^{\circ}$ west of north. Fig. 5a shows the collector from the North and Fig. 5b shows the collector from the East.

According to SAURAN [26], the hour-average direct normal irradiance for Pretoria on 1 January at 10:30 was on average $I=541.7 \mathrm{~W} / \mathrm{m}^{2}$ during 2014 and 2015 . Therefore, the hour-average direct normal irradiance on the tilted surface is obtained as $467.4 \mathrm{~W} / \mathrm{m}^{2}$ by multiplying the DNI with $C$. The hour-average diffuse horizontal irradiance measurement for this location and time was $D=117.5 \mathrm{~W} / \mathrm{m}^{2}$ according to SAURAN [26]. The hour-average diffuse irradiance on the tilted surface is thus calculated as $116.1 \mathrm{~W} / \mathrm{m}^{2}$ by multiplying with $(1+\cos \beta) / 2$, according to Eq. (8). Furthermore, the reflected rays from the ground has an hour-average irradiance of $\rho H(1-\cos \beta) / 2$, which is $1.5 \mathrm{~W} / \mathrm{m}^{2}$. Note that the hour-average global horizontal irradiance was $H=620.9 \mathrm{~W} / \mathrm{m}^{2}$ according to SAURAN [26]. The total hour-average irradiance on the tilted surface is thus $T_{\text {tilt }}=584.6 \mathrm{~W} / \mathrm{m}^{2}$ according to Eq. (8). The validation process aided in the visual inspection and validation of the equations used in the analysis. 


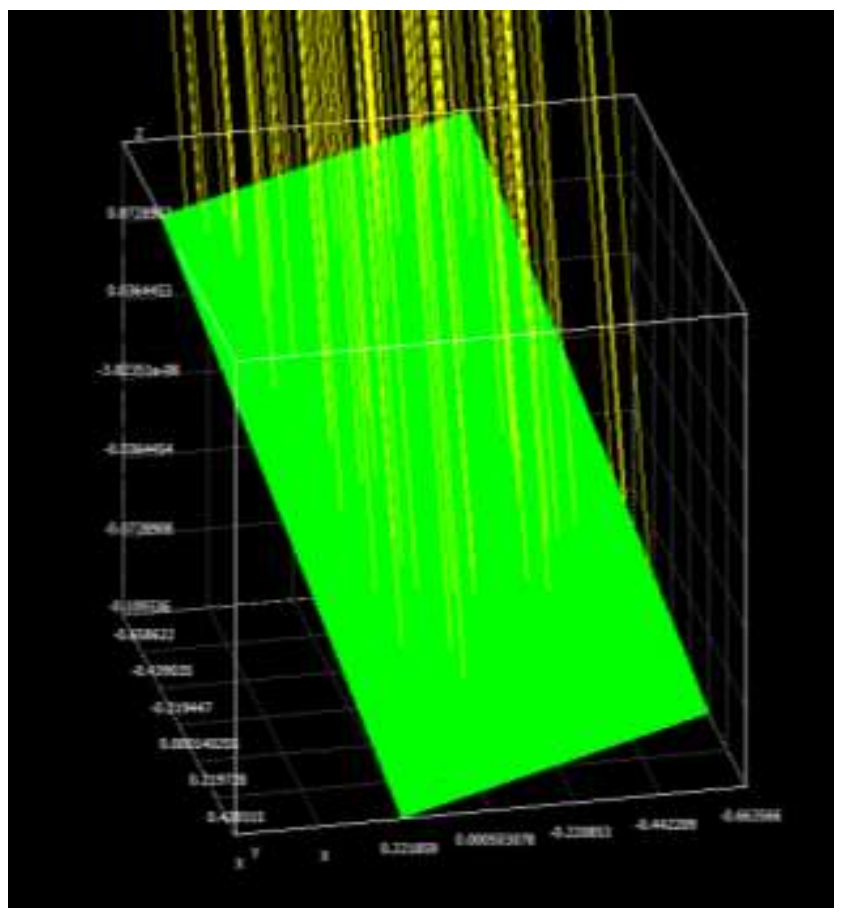

Fig. 4. SolTrace analysis to determine the irradiance on a fixed and tilted surface.

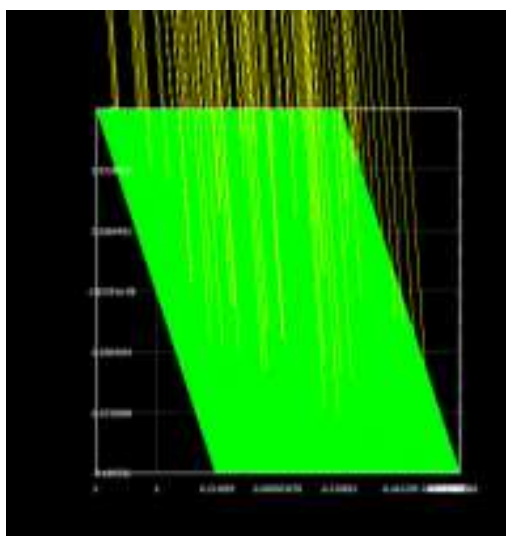

a

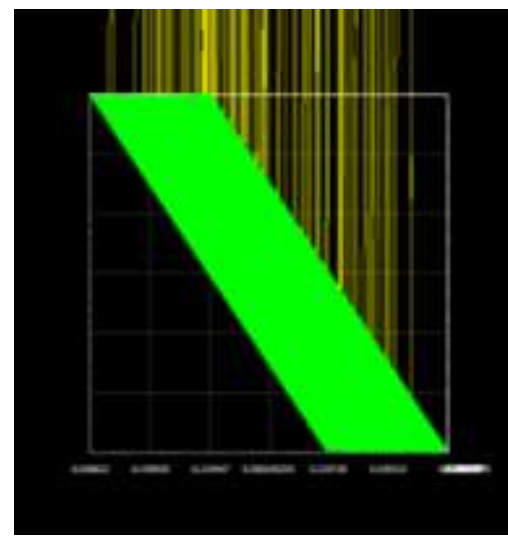

$\mathrm{b}$

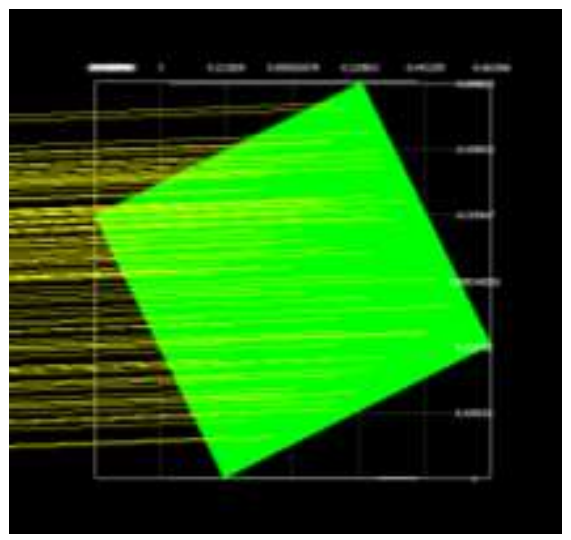

$\mathrm{c}$

Fig. 5. A SolTrace view of the collector in the $X Z$-plane (a), $Y Z$-plane (b) and $X Y$-plane (c).

\subsection{Optimum tilt and azimuth angles}

In the previous section, the analysis of only a single fixed position of a collector in Pretoria on a specific day and time was shown for validation purposes. In this paper, all collector angles and hours of the year were considered to obtain the optimum tilt angle, $\beta_{\text {opt }}$, and optimum azimuth angle, $\Psi_{\text {opt }}$, of a solar collector for maximum insolation, $S_{\text {tilt,max }}$, at each of the different SAURAN locations in South Africa. Tilt angles, $\beta$, from $0^{\circ}$ to $90^{\circ}$, in intervals of $1^{0}$, and azimuth angles, $\Psi$, from $-90^{\circ}$ to $90^{\circ}$, in intervals of $1^{0}$, were investigated for the fixed-collector surface. For an azimuth angle of $0^{0}$, the collector would face north (see 
Fig. 3). Note that the azimuth angle is positive when rotating from north to east and negative when rotating from north to west.

For each of the locations, the annual solar insolation on a tilted surface, $S_{\text {tilt }}$, as shown in Eq. (12), was obtained for all the possible combinations of collector tilt angles, $\beta$, and collector azimuth angles, $\Psi$. The combination of angles which produced the maximum annual solar insolation, $S_{\text {tilt,max }}$, was found. These angles were identified as the optimum collector tilt angle, $\beta_{\text {opt }}$, and the optimum collector azimuth angle, $\Psi_{\text {opt }}$. The surface orientation factor, SOF as shown in Eq. (13), was determined for each combination of $\beta$ and $\Psi$. Contour plots of SOF as a function of $\beta$ and $\Psi$ were developed with the use of Matlab.

\section{Results}

For the eight different locations in South Africa, results of the measured annual insolation using DNI and GHI are shown in Table 2. The percentage error, $\varepsilon$, between measured and calculated annual insolation on a horizontal surface according to Eq. (6) is also shown, where Eq. (4) was used to calculate GHI from the measured DNI and DHI. The maximum percentage error between calculated and measured annual horizontal insolation is $2.8 \%$.

\section{Table 2}

Annual insolation results.

\begin{tabular}{|l|l|l|l|l|l|l|}
\hline Location & $\begin{array}{l}\boldsymbol{S}_{I} \\
\left(\mathbf{k W h} / \mathbf{m}^{2}\right)\end{array}$ & $\begin{array}{l}\boldsymbol{S}_{H} \\
\left(\mathbf{k W h} / \mathbf{m}^{2}\right)\end{array}$ & $\begin{array}{l}\boldsymbol{S}_{H, \text { calc }} \\
\left(\mathbf{k W h} / \mathbf{m}^{2}\right)\end{array}$ & $\boldsymbol{\varepsilon}$ & $\begin{array}{l}\boldsymbol{S}_{I, G S A} \\
\left(\mathbf{k W h} / \mathbf{m}^{2}\right)\end{array}$ & $\begin{array}{l}\boldsymbol{S}_{H, G S A} \\
\left(\mathbf{k W h} / \mathbf{m}^{2}\right)\end{array}$ \\
\hline Bloemfontein & 2649 & 2135 & 2098 & $1.7 \%$ & $2500-2600$ & $2050-2100$ \\
\hline Durban & 1498 & 1609 & 1573 & $2.3 \%$ & $1400-1600$ & $1550-1650$ \\
\hline Graaff-Reinet & 2296 & 1943 & 1928 & $0.8 \%$ & $2300-2400$ & $1900-2000$ \\
\hline Pretoria & 2211 & 2026 & 1994 & $1.6 \%$ & $2000-2100$ & $1950-2050$ \\
\hline Richtersveld & 2737 & 2269 & 2206 & $2.8 \%$ & $2600-2800$ & $2150-2250$ \\
\hline Stellenbosch & 2299 & 1944 & 1898 & $2.4 \%$ & $2100-2300$ & $1850-1950$ \\
\hline $\begin{array}{l}\text { Van } \\
\text { Rhynsdorp }\end{array}$ & 2582 & 2104 & 2058 & $2.2 \%$ & $2500-2600$ & $2050-2100$ \\
\hline Vryheid & 2004 & 1900 & 1852 & $2.6 \%$ & $1800-2000$ & $1850-1950$ \\
\hline
\end{tabular}


As validation, results in Table 2 are compared with data available on DNI and GHI maps of South Africa from GeoSun Africa [38]. These maps were created with SolarGIS which uses satellite and atmospheric data as input and validates output data against ground measurements. These maps are the result of a collaborative effort between Stellenbosch University, the Centre for Renewable and Sustainable Energy Studies (CRSES), GeoSun Africa, GeoModel Solar and GIZ. From inspection of the maps, the measured annual direct normal insolation per location, $S_{I}$, was found to be within $8 \%$ of the mapped data and the measured annual global horizontal insolation, $S_{H}$, within $3 \%$ of the mapped data (Table 2).

Zawilska and Brooks [39] did an assessment of the solar resource for Durban, which is also used for comparison. Zawilska and Brooks [39] found that for Durban, an annual global horizontal insolation, $S_{H}$, of $1624 \mathrm{kWh} / \mathrm{m}^{2}$ and an annual direct normal insolation, $S_{I}$, of $1850 \mathrm{kWh} / \mathrm{m}^{2}$ can be expected. The annual direct normal insolation value is higher than the results found for Durban in Table 2. It should be noted that the two Durban measuring stations considered in this work are located west of Durban, while Zawilska and Brooks [39] used measured data from a station located south of Durban. From inspection of the DNI map from GeoSun Africa [38], solar irradiance levels west of Durban are considered to be lower than for other places in Durban. According to Zawilska and Brooks [39], annual global horizontal insolation for Pretoria should be $1986 \mathrm{kWh} / \mathrm{m}^{2}$, which compares well with the results for Pretoria in Table 2.

\section{Table 3}

Solar insolation on a solar-tracking collector.

\begin{tabular}{|l|l|l|}
\hline Location & $\begin{array}{l}\boldsymbol{S}_{\text {track }} \\
\left(\mathbf{k W h} / \mathbf{m}^{\mathbf{2}}\right)\end{array}$ & $\boldsymbol{S}_{\text {track }} / \boldsymbol{S}_{\text {H,calc }}$ \\
\hline Bloemfontein & 3179 & 1.51 \\
\hline Durban & 2124 & 1.35 \\
\hline Graaff-Reinet & 2840 & 1.47 \\
\hline Pretoria & 2832 & 1.42 \\
\hline Richtersveld & 3241 & 1.47 \\
\hline Stellenbosch & 2812 & 1.48 \\
\hline Van Rhynsdorp & 3074 & 1.49 \\
\hline Vryheid & 2627 & 1.42 \\
\hline
\end{tabular}


Table 3 shows the calculated annual insolation, $S_{\text {track }}$, for a two-axis solar-tracking surface. The increase in solar insolation when using a solar-tracking collector instead of a horizontally-fixed collector, $S_{\text {track }} / S_{H, \text { calc }}$, is also shown. Table 3 shows that a solar-tracking collector can increase the solar insolation with between $35 \%$ and $51 \%$. On average, a solartracking collector in South Africa can collect 45\% more annual solar insolation than a horizontally-fixed collector.

\section{Table 4}

Solar insolation on an optimally-fixed collector.

\begin{tabular}{|l|l|l|l|l|}
\hline Location & $\boldsymbol{\beta}_{\text {opt }}$ & $\boldsymbol{\Psi}_{\text {opt }}$ & $\begin{array}{l}\boldsymbol{S}_{\text {tilt,max }} \\
\left(\mathbf{k W h} / \mathbf{m}^{2}\right)\end{array}$ & $\boldsymbol{S}_{\text {tilt,max }} / \boldsymbol{S}_{\text {H,calc }}$ \\
\hline Bloemfontein & $28^{0}$ & $6^{0}$ & 2317 & 1.10 \\
\hline Durban & $29^{0}$ & $8^{0}$ & 1734 & 1.10 \\
\hline Graaff-Reinet & $29^{0}$ & $-7^{0}$ & 2136 & 1.11 \\
\hline Pretoria & $27^{0}$ & $4^{0}$ & 2176 & 1.09 \\
\hline Richtersveld & $26^{0}$ & $-14^{0}$ & 2404 & 1.09 \\
\hline Stellenbosch & $27^{0}$ & $-4^{0}$ & 2073 & 1.09 \\
\hline Van Rhynsdorp & $27^{0}$ & $-12^{0}$ & 2255 & 1.10 \\
\hline Vryheid & $29^{0}$ & $1^{0}$ & 2048 & 1.11 \\
\hline
\end{tabular}

Table 5

Optimum tilt and azimuth rotation angles compared with similar work.

\begin{tabular}{|l|l|l|l|l|l|l|l|}
\hline \multirow{2}{*}{ Location } & \multicolumn{2}{|l|}{ Current work } & \multicolumn{2}{l|}{ Suri et al. [1] } & \multicolumn{2}{l|}{ Bekker [2] } & Latitude \\
\cline { 2 - 8 } & $\boldsymbol{\beta}_{\text {opt }}$ & $\boldsymbol{\Psi}_{\text {opt }}$ & $\boldsymbol{\beta}_{\text {opt }}$ & $\boldsymbol{\Psi}_{\text {opt }}$ & $\boldsymbol{\beta}_{\text {opt }}$ & $\boldsymbol{\Psi}_{\text {opt }}$ & $\boldsymbol{\beta}_{\text {opt }}$ \\
\hline Bloemfontein & $28^{0}$ & $6^{0}$ & $29^{0}$ & $0^{0}$ & - & - & $29.1^{0}$ \\
\hline Durban & $29^{0}$ & $8^{0}$ & $30.5^{0}$ & $0^{0}$ & $30^{0}$ & $10^{0}$ & $29.9^{0}$ \\
\hline Graaff-Reinet & $29^{0}$ & $-7^{0}$ & $30^{0}$ & $0^{0}$ & - & - & $32.5^{0}$ \\
\hline Pretoria & $27^{0}$ & $4^{0}$ & $27^{0}$ & $0^{0}$ & $30^{0}$ & $10^{0}$ & $25.7^{0}$ \\
\hline Richtersveld & $26^{0}$ & $-14^{0}$ & $26.5^{0}$ & $0^{0}$ & - & - & $28.6^{0}$ \\
\hline Stellenbosch & $27^{0}$ & $-4^{0}$ & $29.5^{0}$ & $0^{0}$ & - & - & $33.9^{0}$ \\
\hline Van Rhynsdorp & $27^{0}$ & $-12^{0}$ & $28.5^{0}$ & $0^{0}$ & - & - & $31.6^{0}$ \\
\hline Vryheid & $29^{0}$ & $1^{0}$ & $29^{0}$ & $0^{0}$ & - & - & $27.8^{0}$ \\
\hline
\end{tabular}


Table 4 shows the calculated annual insolation, $S_{\text {tilt,max }}$, for a surface which is fixed at an optimum tilt and azimuth angle. Table 4 also shows the optimum fixed solar collector tilt angles and optimum fixed azimuth angles for the eight locations considered. These results were obtained by considering all collector tilt angles from $0^{\circ}$ to $90^{\circ}$ and collector azimuth angles from $-90^{\circ}$ to $90^{\circ}$ in the analysis to determine the angles which would provide maximum annual insolation according to the measured solar data. The increase in solar insolation, $S_{\text {tilt,max }} / S_{H, \text { calc }}$, when using an optimally-fixed collector instead of a horizontallyfixed collector is also shown in Table 4. Results show that a collector fixed at the optimum tilt and azimuth angle can increase the annual solar insolation with between $9 \%$ and $11 \%$. On average, an optimally positioned fixed installation in South Africa can collect $10 \%$ more annual solar insolation than a horizontally-fixed collector.

As shown in Table 5, results for the optimum tilt angle compare very well with results from Suri et al. [1]. Results are within $1^{\circ}$, except for Durban (within $1.5^{\circ}$ ), Van Rhynsdorp (within $1.5^{\circ}$ ) and Stellenbosch (within $2.5^{\circ}$ ). It should be noted that Suri et al. [1] did not investigate azimuth rotation angle and fixed the collector towards the North $\left(0^{0}\right)$. Optimum tilt angles for Durban and Pretoria, available from Bekker [2], also compare well with the current work. According to the Heywood and Chinnery equations, the optimum tilt angle of a solar collector would be the same as the latitude angle of the location [3,21]. The optimum tilt angles found for the eight locations do compare well with the latitude angle as shown in Table 5. The optimum tilt angles are within $2.6^{\circ}$ of the latitude, except for Graaff-Reinet (within $3.5^{\circ}$ ), Van Rhynsdorp (within $4.6^{\circ}$ ) and Stellenbosch (within $6.9^{\circ}$ ).

The optimum azimuth angles for the locations considered are also shown in Fig. 6. It was found that the optimum azimuth angle can be approximated with a sinusoidal function of the longitude angle minus the absolute latitude angle, $\sigma$. The optimum azimuth angle can be approximated with Eq. (18) where the root-mean-square error is $1.36^{\circ}$. Note that Eq. (18) is only suggested for the area between latitude angles of $-25.75^{\circ}$ and $-33.93^{\circ}$ and between longitude angles of $16.76^{\circ}$ and $30.98^{\circ}$. However, more measured solar data from other locations across South Africa would be required for verification.

$$
\Psi_{o p t}=12 \sin (18 \sigma+105)-2
$$

Fig. 7 shows the optimum azimuth angle results as a function of the longitude angle minus the absolute latitude angle compared with the optimum azimuth angles found by Bekker [2] 
at other locations across South Africa. Fig. 7 does not suggest a sinusoidal function, but rather that solar collectors at locations in South Africa where $\sigma>-7^{0}$ should face a few degrees east of north while collectors at locations where $\sigma<-7^{0}$ should face a few degrees west of north. Bekker [2] suggested that for locations exposed to frontal weather systems like Cape Town, the azimuth angle should be adjusted towards the West, while for locations exposed to convective precipitation, like Pretoria, the azimuth should be adjusted towards the East. This suggestion is in line with the current work. Frontal systems originate over the Atlantic Ocean and approach South Africa from the South-West, while thunderstorms over the interior tend to build up during the afternoons when the sun is in the West.

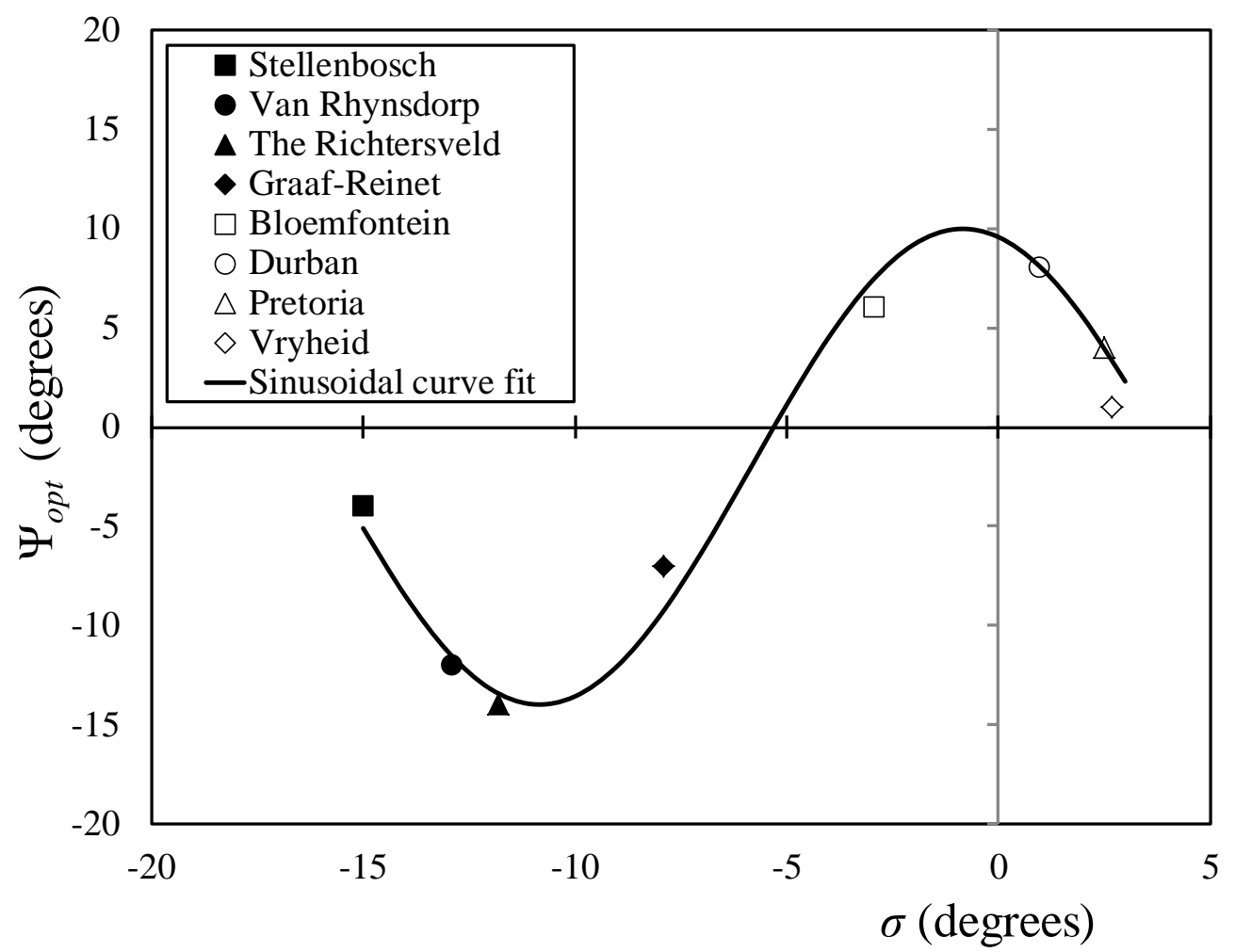

Fig. 6. Optimum azimuth angle as a function of the longitude angle minus the absolute latitude angle.

The optimum tilt angles and azimuth angles suggested by Matshoge and Sebitosi [22] for South African locations do not compare well with the results in Table 5. In their work, effects such as wind and wind direction relative to photovoltaic panels were included so that panels can be cooled effectively. Matshoge and Sebitosi [22] noted a general trend of increasing optimum tilt and azimuth angle from west to east. 


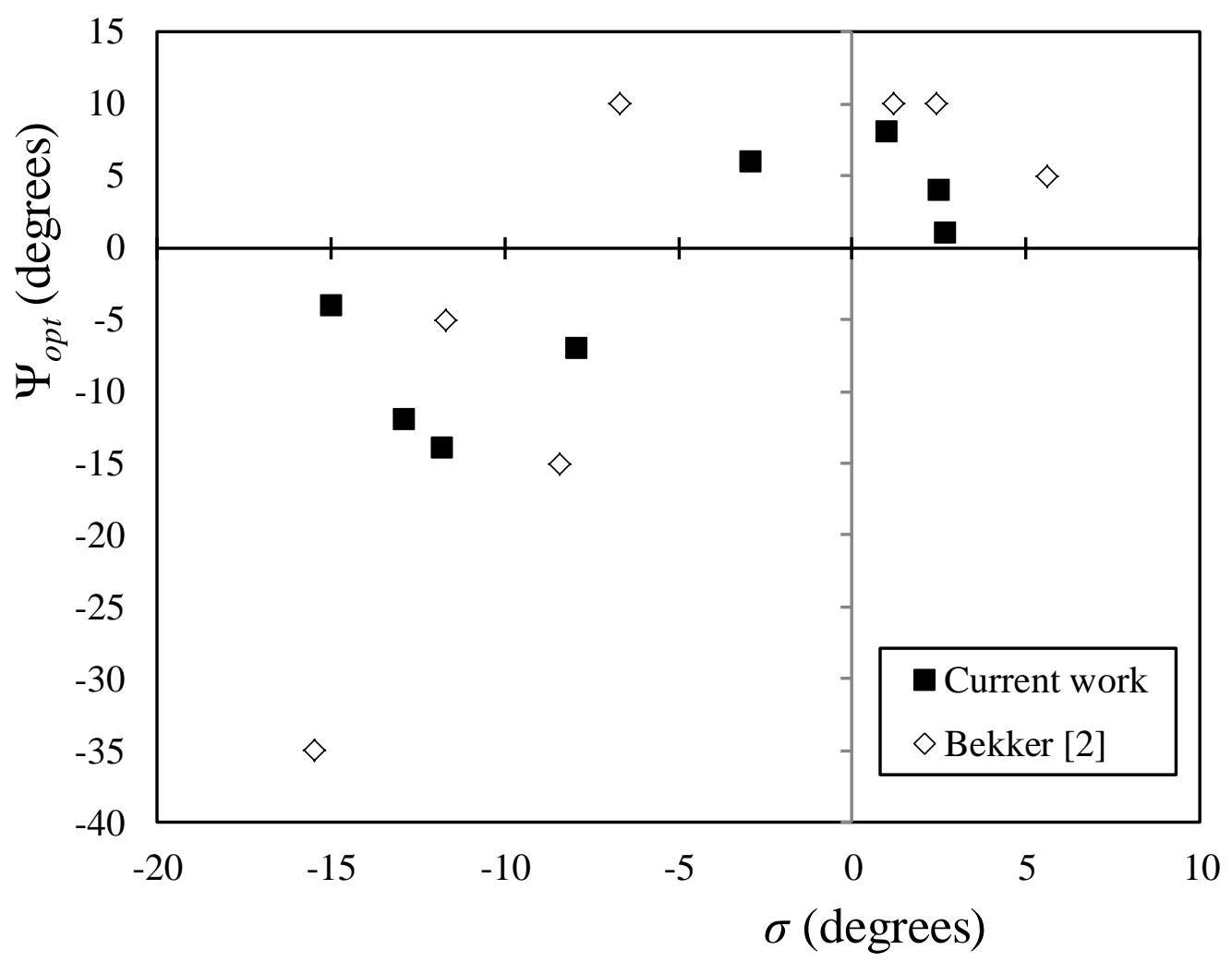

Fig. 7. Comparison of the optimum azimuth angle as a function of the longitude angle minus the absolute latitude angle.

Figs. 8-15 show the effects of rotating and tilting a surface along the azimuth angle and elevation angle, respectively, in terms of the surface orientation factor as shown in Eq. (13). In these figures, the surface orientation factor, $S O F$, is shown as a function of the collector tilt angle $\left(0^{\circ} \leq \beta \leq 90^{\circ}\right)$ and collector azimuth angle $\left(-90^{\circ} \leq \Psi \leq 90^{\circ}\right)$ in the form of contour plots. The optimum collector tilt and azimuth angles for maximum annual solar insolation are found at $S O F=1$. For example, according to Fig. 8, the maximum annual solar insolation on a collector in Bloemfontein would be found by tilting the collector at an angle of about $28^{\circ}$ and by rotating the collector to an azimuth angle of about $6^{\circ}$ east of north. This is similar to the results shown in Table 4 and Table 5.

Note that for all locations, it is beneficial to tilt the surface at an angle of $\beta=30^{\circ}$ and let it face north $\left(\Psi=0^{\circ}\right)$. For all locations, this would ensure that the annual insolation is within $98 \%$ of the maximum obtainable insolation for a fixed installation. Note that even when the surface is tilted at an angle of $20^{\circ}$ instead of $30^{\circ}$ and faces north, the annual insolation is still within $98 \%$ of the maximum. For all the locations, the annual insolation for a horizontal 
collector (where $\beta=0^{\circ}$ ) is within $90 \%$ of the maximum annual insolation of an optimallyfixed and tilted collector.

The optimum tilt angle and azimuth angle can be found easily from these contour plots. The contour plots allow one to determine the cost-effectiveness of fixing a collector at a certain tilt and azimuth angle against fixing it horizontally at lower cost. Results from the considered locations show that an optimally positioned fixed installation can, on average, collect $10 \%$ more annual solar insolation than a horizontally-fixed collector. With this information, the cost-effectiveness of building an extra structure to position a collector at the optimum fixed angles can be determined by taking the lifetime of the collector into consideration. The contour plots can also be used to determine the annual solar insolation of fixed surfaces of buildings.

Note that in Figs. 8-15, true north is at an azimuth angle of $0^{\circ}$. A compass can be used to determine the azimuth angle when fixing a solar collector; however, the slight magnetic declination should usually be accounted for. Figs. 8-15 show that even if a magnetic declination is not accounted for, the fixed-collector surface would still receive an insolation of within $98 \%$ of the maximum.

Contour plots of Bloemfontein, Durban, Pretoria and Vryheid show that it is beneficial for a fixed installation to face north and be mounted slightly towards the East, as was also shown in Table 4, Table 5, Fig. 6 and Fig. 7. For Graaff-Reinet, the Richtersveld, Stellenbosch and Van Rhynsdorp, contour plots show that fixed installations should face north and be mounted slightly towards the West. It should be noted that most of the locations had more than 26 months' data available at the time of writing the paper; however, it is suggested that a similar study be done after a few years to update and compare the results. 


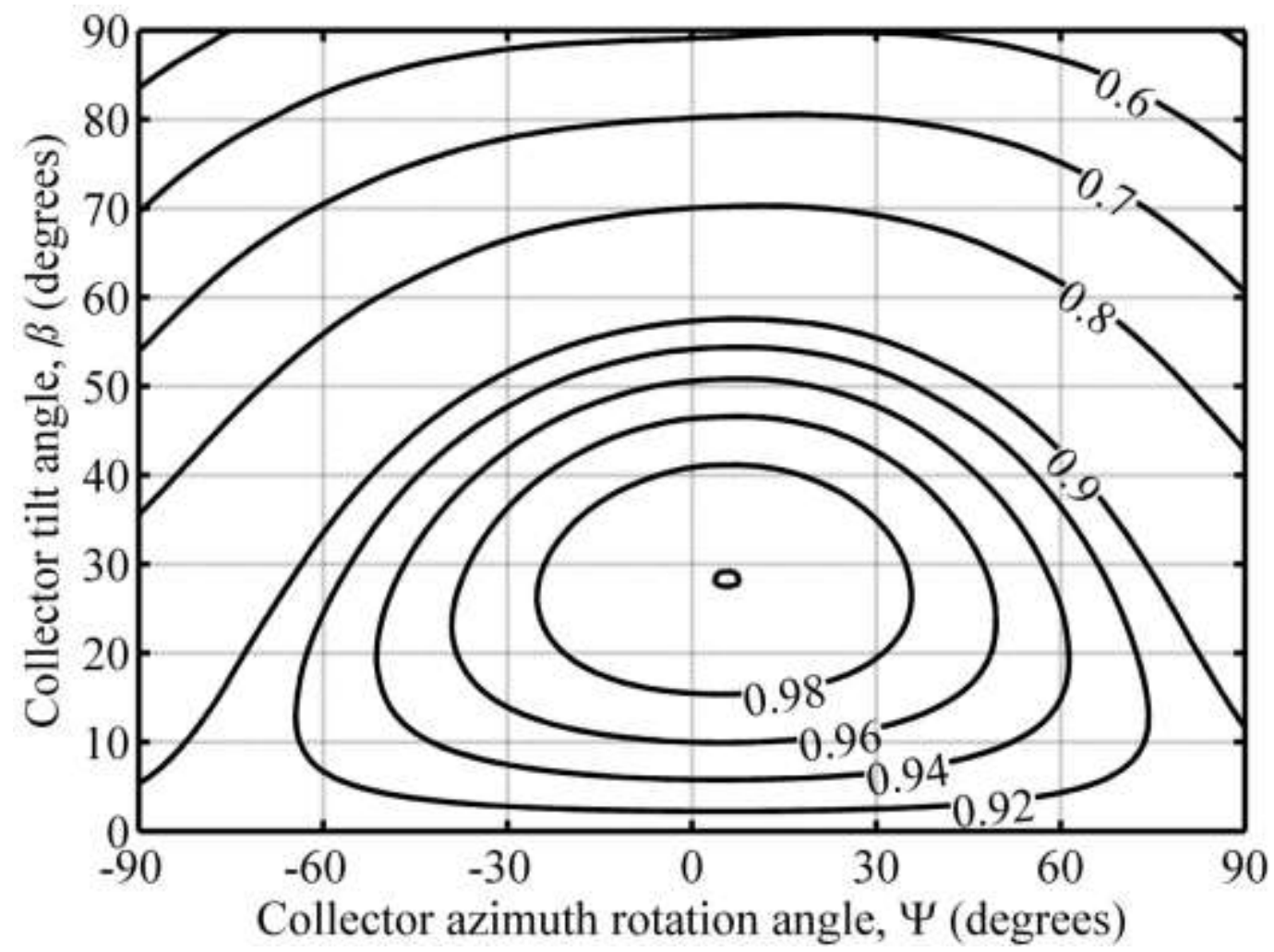

Fig. 8. Contour plot of $S O F=S_{\text {tilt }} / S_{\text {tilt,max }}$ for fixed collector surfaces in Bloemfontein.

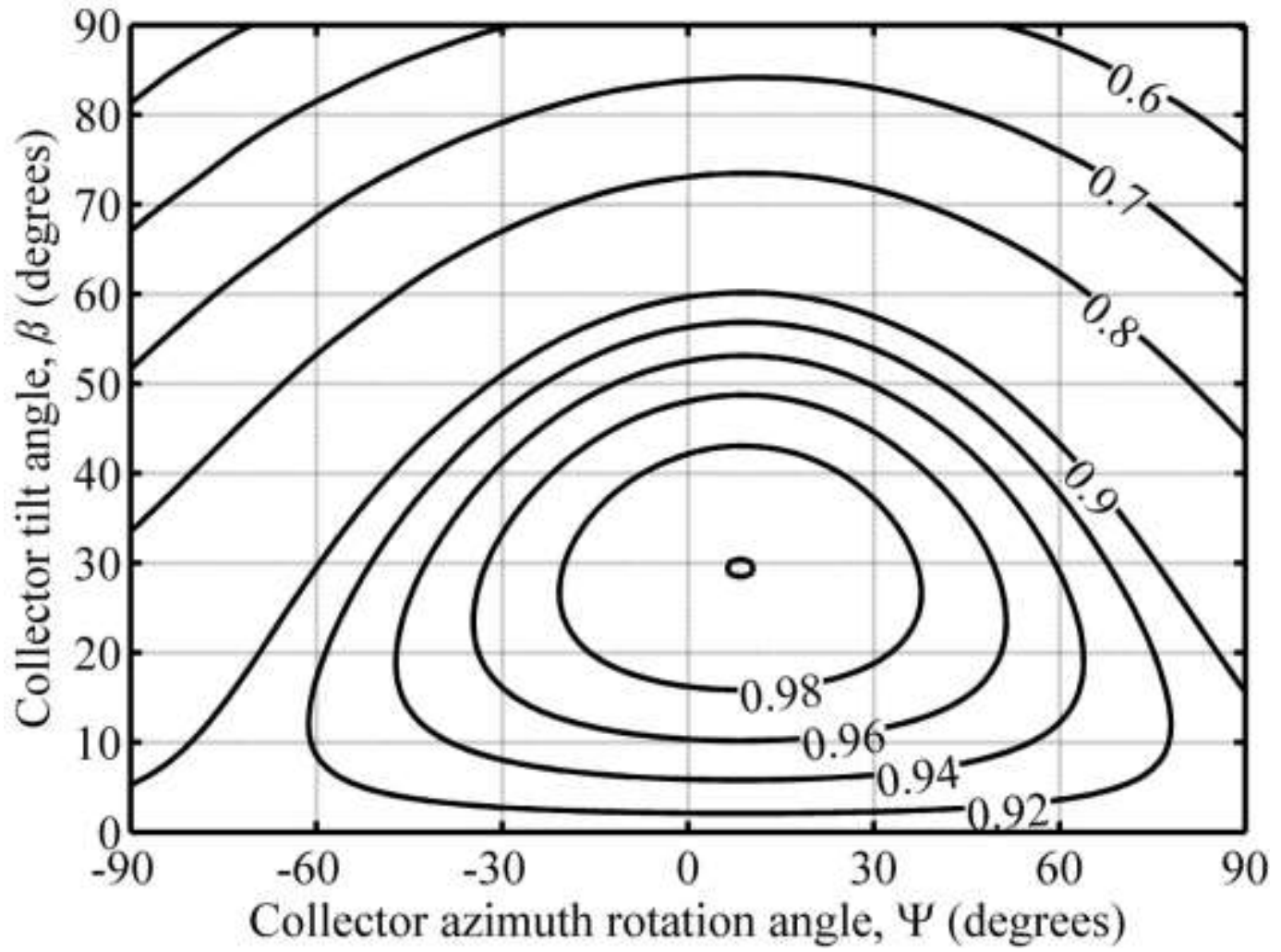

Fig. 9. Contour plot of $S O F=S_{\text {tilt }} / S_{\text {tilt,max }}$ for fixed collector surfaces in Durban. 


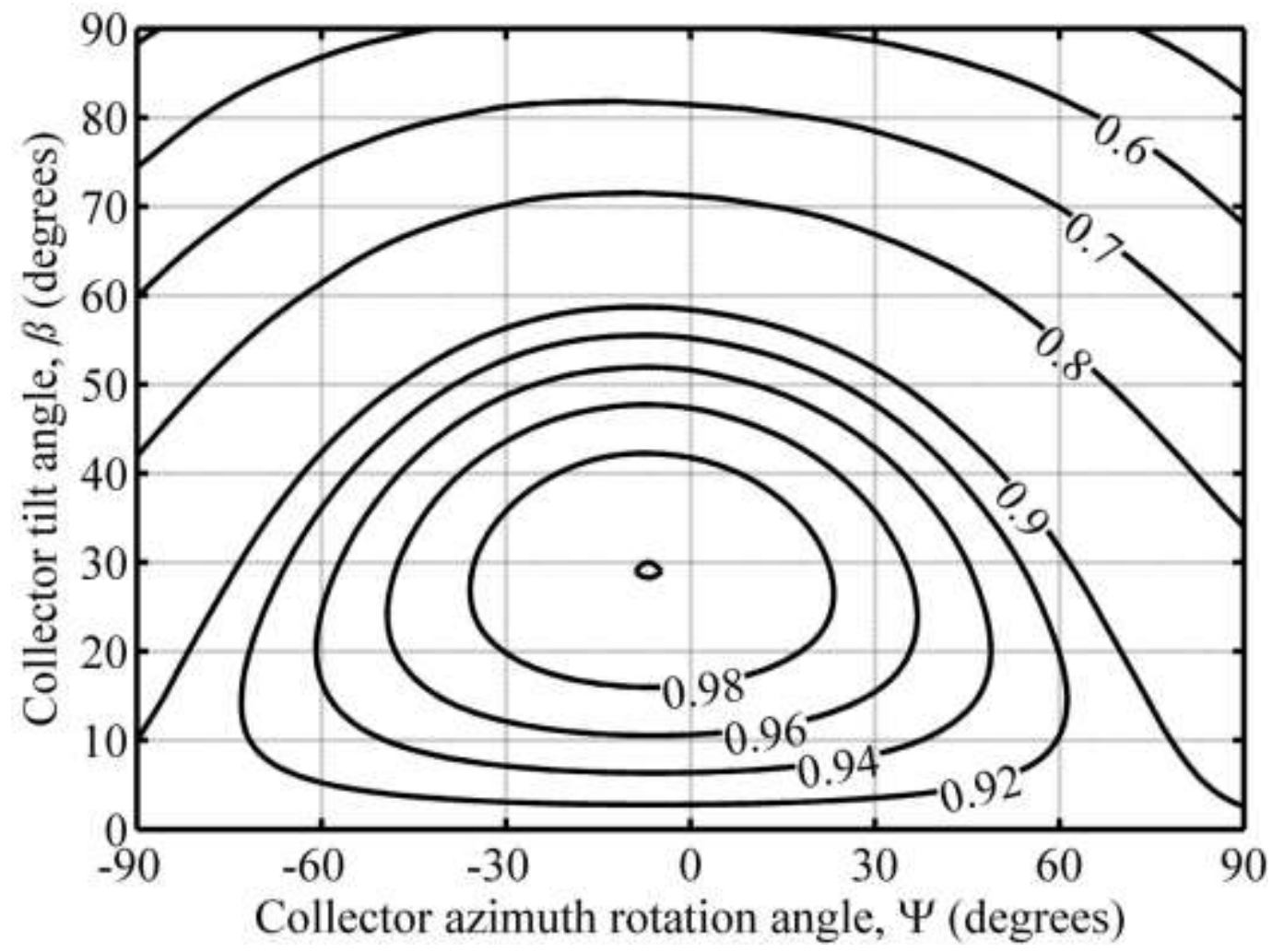

Fig. 10. Contour plot of $S O F=S_{\text {tilt }} / S_{\text {tilt,max }}$ for fixed collector surfaces in Graaff-Reinet.

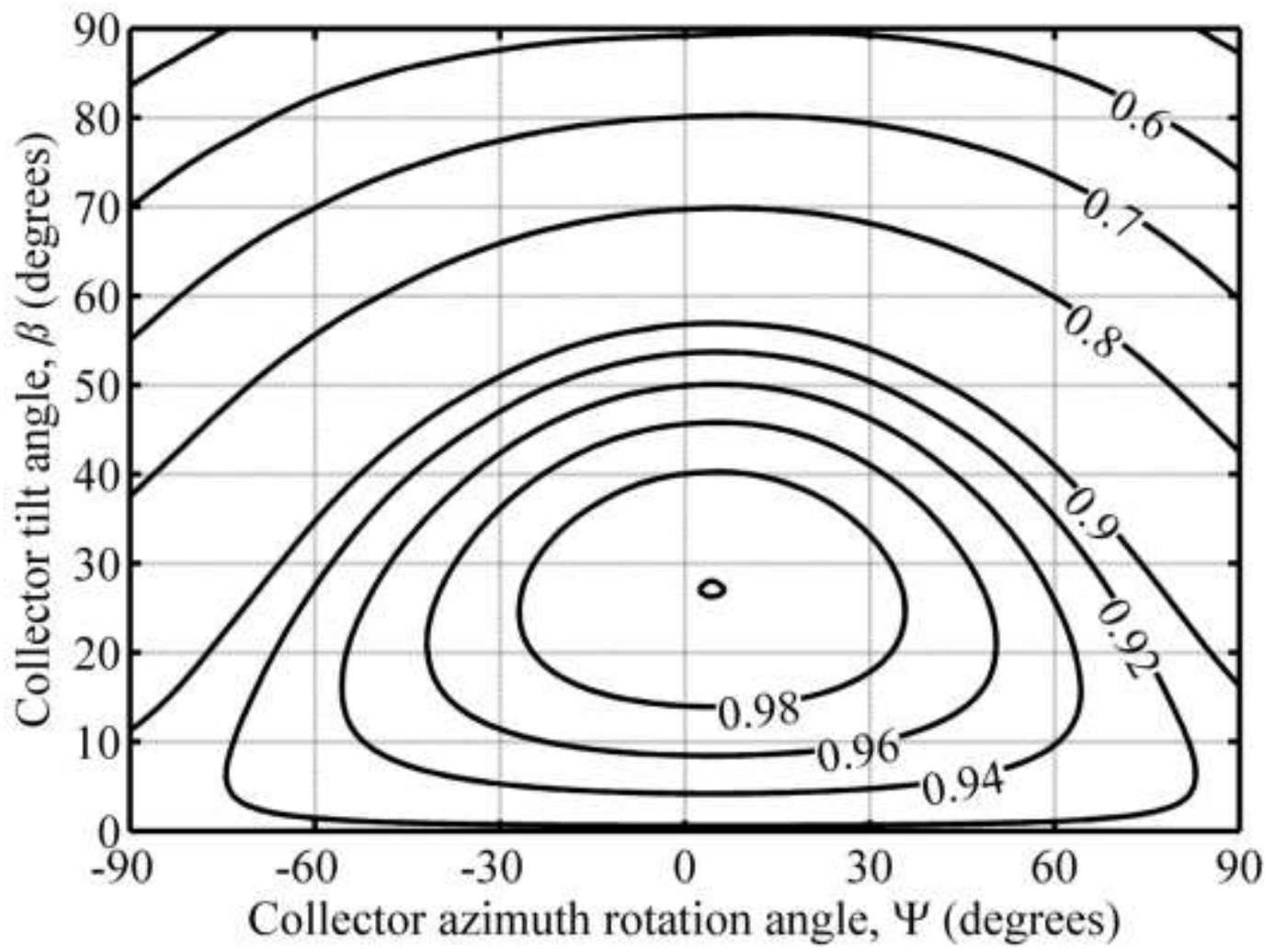

Fig. 11. Contour plot of $S O F=S_{\text {tilt }} / S_{\text {tilt,max }}$ for fixed collector surfaces in Pretoria. 


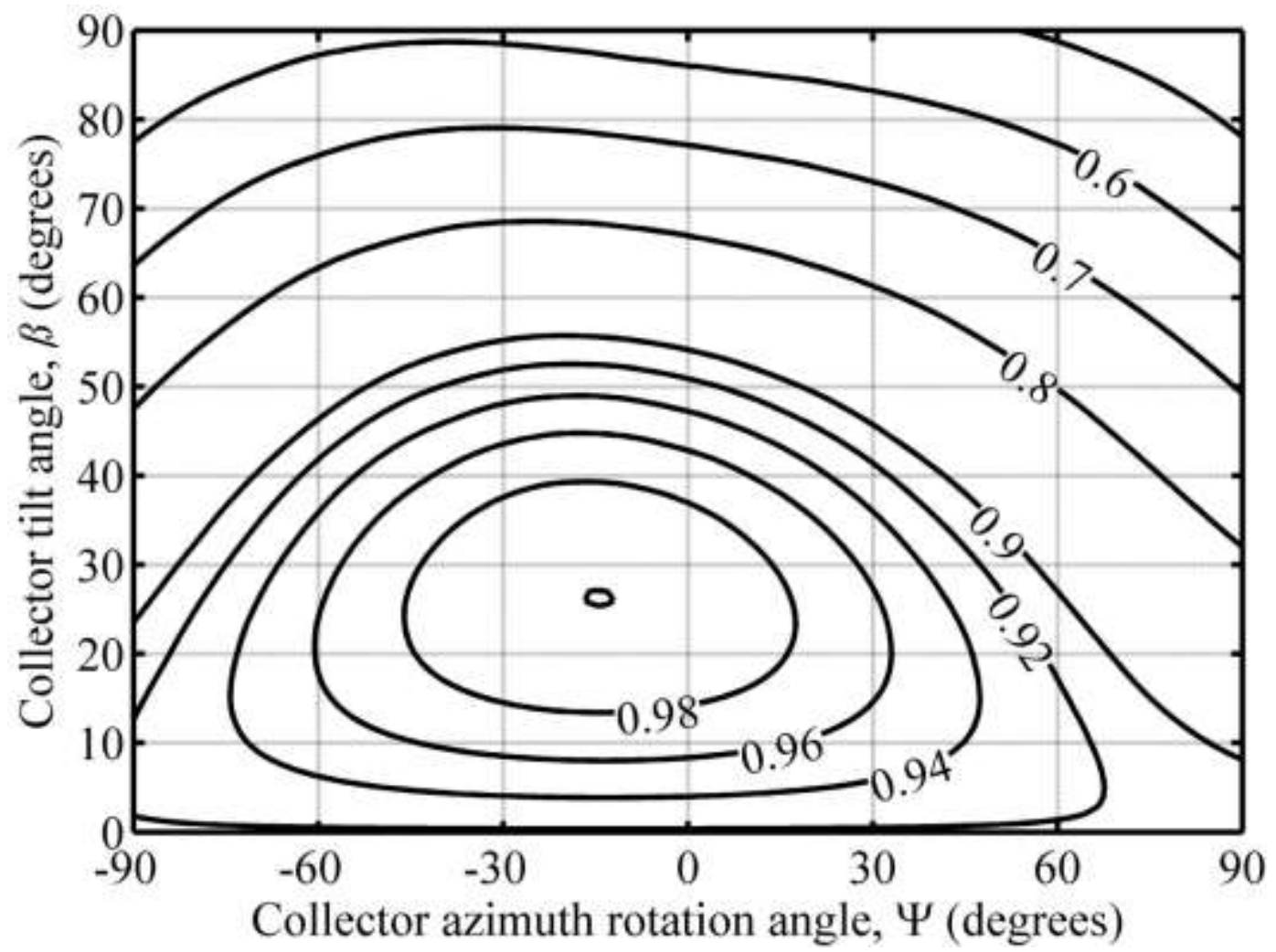

Fig. 12. Contour plot of $S O F=S_{\text {tilt }} / S_{\text {tilt,max }}$ for fixed collector surfaces in the Richtersveld.

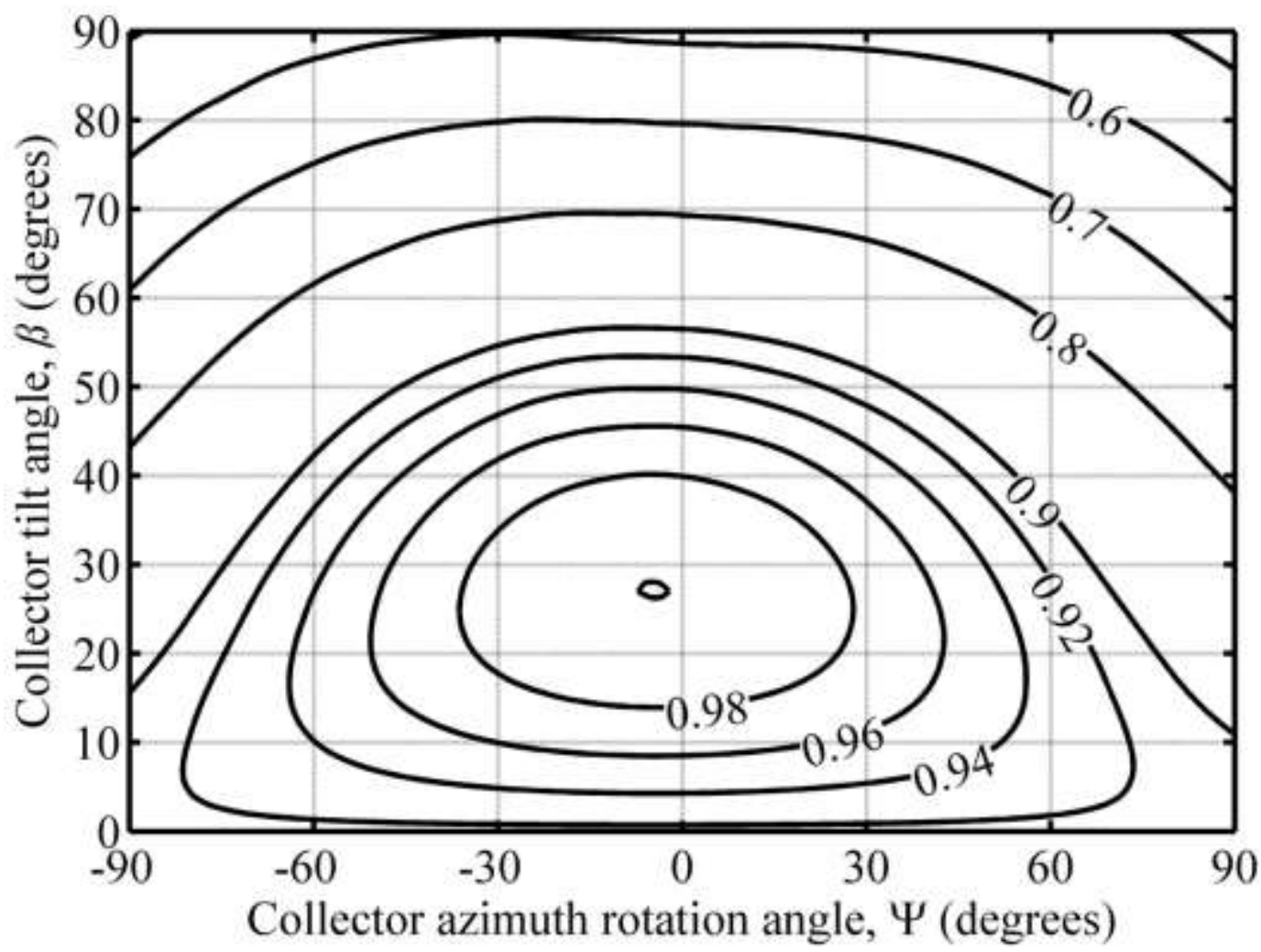

Fig. 13. Contour plot of $S O F=S_{\text {tilt }} / S_{\text {tilt,max }}$ for fixed collector surfaces in Stellenbosch. 


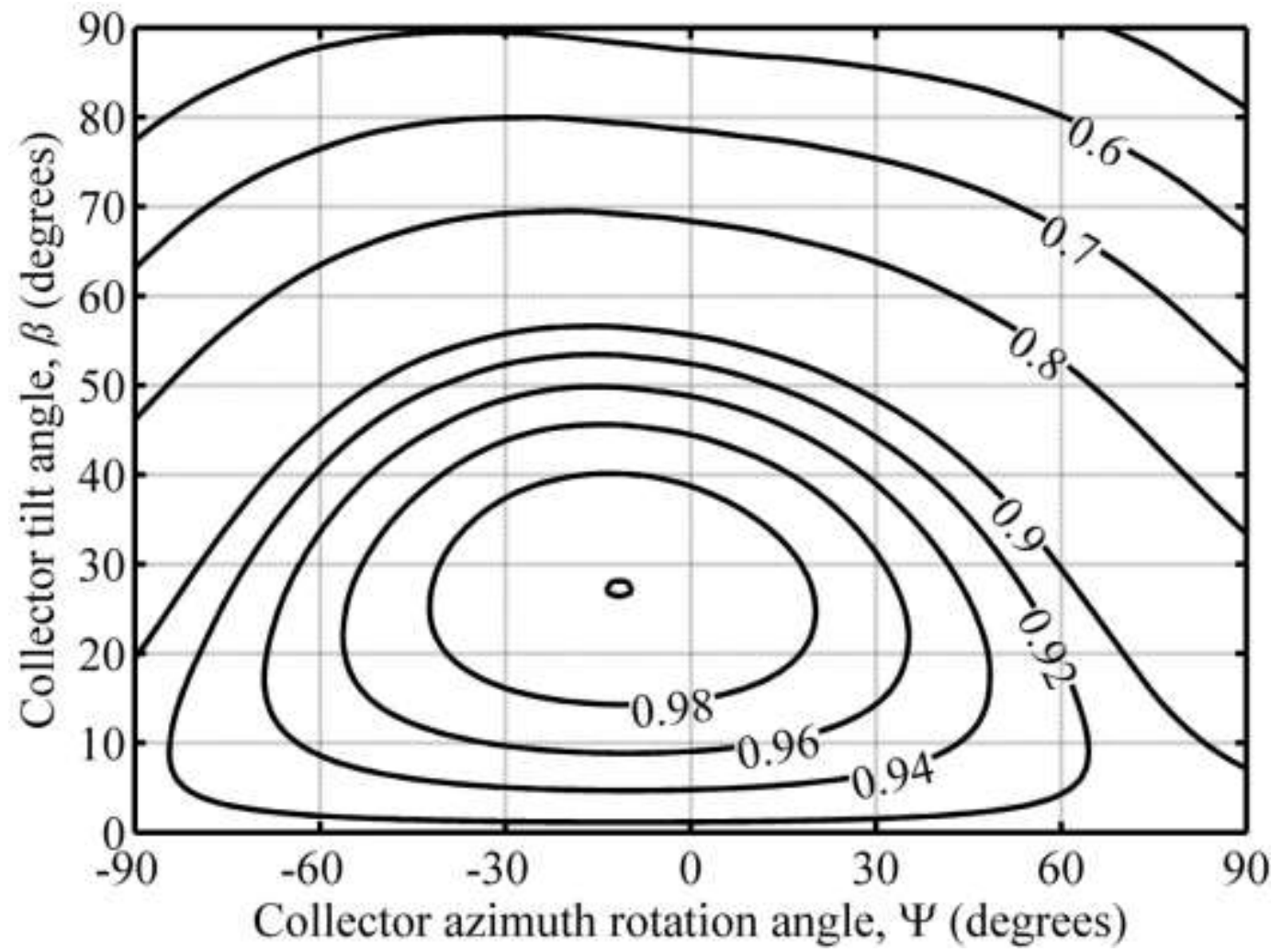

Fig. 14. Contour plot of $S O F=S_{\text {tilt }} / S_{\text {tilt,max }}$ for fixed collector surfaces in Van Rhynsdorp.

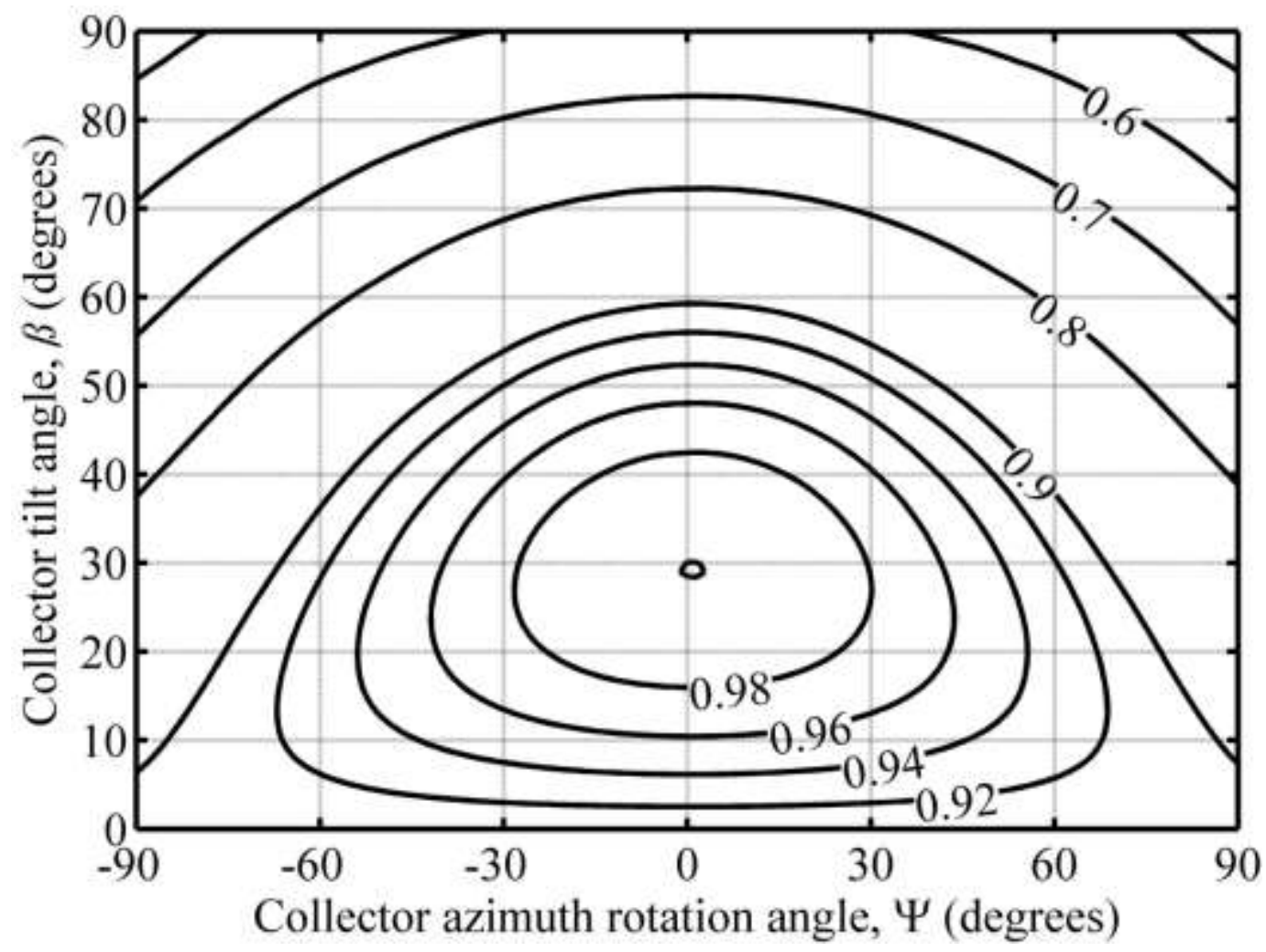

Fig. 15. Contour plot of $S O F=S_{\text {tilt }} / S_{\text {tilt,max }}$ for fixed collector surfaces in Vryheid. 


\section{Conclusion}

The solar resource in South Africa is among the best in the world. In the past few years, South Africa has seen an increase in local and foreign investment in solar power plants, solar water heaters and photovoltaic panels. This justifies the need for the accurate determination of the optimum angles of fixed solar collectors. Data from nine solar measuring stations across South Africa was used to calculate the annual solar insolation on fixed collectors, at all possible installation angles, as well as the annual solar insolation on solar-tracking collectors. SolTrace was used to validate the calculations.

Results showed that the annual solar insolation of a solar-tracking collector in South Africa can, on average, be $45 \%$ more than a horizontally-fixed collector. Furthermore, results showed that an optimally positioned fixed installation can, on average, collect $10 \%$ more annual solar insolation than a horizontally-fixed collector. The optimum fixed angles at which solar collectors should be positioned to capture the most solar energy in a typical year's time were found. The optimum angle of tilt is similar to the latitude of the location and the optimum azimuth angle is a function of the longitude angle minus the absolute latitude angle, $\sigma$. This result suggests that solar collectors at locations in South Africa exposed to convective precipitation, where $\sigma>-7^{0}$, should face slightly east of north with a maximum of $8^{\circ}$ in Durban. Collectors at locations exposed to frontal weather systems, where $\sigma<-7^{0}$, should face slightly west of north with a maximum of $14^{\circ}$ in the Richtersveld.

Contour plots were used to present the effects of tilt angle and azimuth rotation angle on annual solar insolation over a range of collector tilt and azimuth angles from horizontal to vertical and from east to west. The contour plots allow one to determine the costeffectiveness of having a structure to fix a collector at a certain tilt and azimuth angle against fixing it horizontally. The contour plots can also be used to determine the annual solar insolation of fixed surfaces of buildings.

From the measured data of the considered locations it is concluded that any solar collector in South Africa facing north (magnetic or true north), with a tilt angle of $30^{\circ}$, should be able to capture $98 \%$ of the maximum annual solar insolation which is achievable with an optimallyfixed installation. The results are relevant for all solar-collection technologies. It should be noted that most of the solar measuring stations which were considered in this work were installed recently, which was excellent in terms of accuracy but limiting in terms of available 
data. It is recommended that a similar study be done in a few years when more data is available.

\section{Acknowledgement}

The author acknowledges the Southern African Universities Radiometric Network (SAURAN) as well as the devoted students and volunteers who clean the solar measuring equipment three times per week.

\section{References}

[1] Suri M., Cebecauer T., Skoczek A., 2012. Solar electricity production from fixedinclined and sun-tracking c-Si photovoltaic modules in South Africa. In: Proceedings of the $1^{\text {st }}$ Southern African Solar Energy Conference (SASEC 2012), 21-23 May, Stellenbosch, South Africa.

[2] Bekker, B., 2007. Irradiation and PV array energy output, cost, and optimal positioning estimation for South Africa. Journal of Energy in Southern Africa, Vol. 18(2), pp. 1625 .

[3] Stanciu, C., Stanciu, D., 2014. Optimum tilt angle for flat plate collectors all over the world - a declination dependence formula and comparisons of three solar radiation models. Energy Conversion and Management, Vol. 81, pp.133-143.

[4] Gopinathan, K.K., 1991. Solar radiation on variously oriented sloping surfaces. Solar Energy, Vol. 47(3), pp. 173-179.

[5] Ibrahim, D., 1995. Optimum tilt angle for solar collectors used in Cyprus. Renewable Energy, Vol. 6(7), pp. 813-819.

[6] Morcos, V.H., 1994. Optimum tilt angle and orientation for solar collectors in Assiut, Egypt. Renewable Energy, Vol. 4(3), pp. 291-298.

[7] Yakup, M.A.b.H.M., Malik, A.Q., 2001. Optimum tilt angle and orientation for solar collector in Brunei Darussalam. Renewable Energy, Vol. 24, pp. 223-234.

[8] Tang, R., Wu, T., 2004. Optimal tilt-angles for solar collectors used in China. Applied Energy, Vol. 79, pp. 239-248. 
[9] Kamali, G.A., Moradi I., Khalili, A., 2006. Estimating solar radiation on tilted surfaces with various orientations: a study case in Karaj (Iran). Theoretical and Applied Climatology, Vol. 84, pp. 235-241.

[10] Chandel, S.S., Aggarwal, R.K., 2011. Estimation of hourly solar radiation on horizontal and inclined surfaces in western Himalayas. Smart Grid and Renewable Energy, Vol. 2, pp. 45-55.

[11] Ahmad, M.J., Tiwari, G.N., 2009. Optimization of tilt angle for solar collector to receive maximum radiation. The Open Renewable Energy Journal, Vol. 2, pp. 19-24.

[12] Ng, K.M., Adam, N.M., Inayatullah, O., Ab Kadir, M.Z.A., 2014. Assessment of solar radiation on diversely oriented surfaces and optimum tilts for solar absorbers in Malaysian tropical latitude. International Journal of Energy and Environmental Engineering, Vol. 5(5), pp. 1-13.

[13] Jakhrani, A.Q., Othman, A., Rigit, A.R.H., Samo, S.R., Kamboh, S.A., 2012. Estimation of incident solar radiation on tilted surface by different empirical models. International Journal of Scientific and Research Publications, Vol. 2(12), pp. 1-6.

[14] Jakhrani, A.Q., Samo, S.R., Rigit, A.R.H., Kamboh, S.A., 2013. Selection of models for calculation of incident solar radiation on tilted surfaces. World Applied Sciences Journal, Vol. 22(9), pp. 1334-1343.

[15] Marion, W., Wilcox, S., 1995. Solar radiation data manual for flat-plate and concentrating collectors. Colorado: National Renewable Energy Laboratory (NREL).

[16] Manes, A., Ianetz, A., 1983. On the optimum exposure of flat-plate fixed solar collectors. Solar Energy, Vol. 31(1), pp. 21-27.

[17] Handoyo, E.A., Ichsani D., Prabowo, 2013. The optimal tilt angle of a solar collector. Energy Procedia, Vol. 32, pp. 166-175.

[18] Bilbao, J., De Miguel, A., Ayuso, A., Franco, J.A., 2003. Iso-radiation maps for tilted surfaces in the Castile and Leon region, Spain. Energy Conversion and Management, Vol. 44, pp. 1575-1588.

[19] Beringer, S. Schilke, H., Lohse, I., Seckmeyer, G., 2001. Case study showing that the tilt angle of photovoltaic plants is nearly irrelevant. Solar Energy, Vol. 85, pp. 470-476.

[20] Asl-Soleimani, E., Farhangi, S., Zabihi, M.S., 2001. The effect of tilt angle, air pollution on performance of photovoltaic systems in Tehran. Renewable Energy, Vol. 24, pp. 459-468. 
[21] Asowata, O., Swart, J., Pienaar, C., 2012. Optimum tilt angles for photovoltaic panels during winter months in the Vaal Triangle, South Africa. Smart Grid and Renewable Energy, Vol. 3, pp. 119-125.

[22] Matshoge, T., Sebitosi, A.B., 2010. The mapping of maximum annual energy yield azimuth and tilt angles for photovoltaic installations at all locations in South Africa. Journal of Energy in Southern Africa, Vol. 21(4), pp. 1-6.

[23] Kern, J., Harris, I., 1975. On the optimum tilt of a solar collector. Solar Energy, Vol. 17, pp. 97-102.

[24] Christensen, C.B., Barker, G.M., 2001. Effects of tilt and azimuth on annual incident solar radiation for United States locations. In: Proceedings of Solar Forum 2001: Solar Energy: The Power to Choose, April 21-25, Washington, DC.

[25] Li, D.H.W., Lam, T.N.T., 2007. Determining the optimum tilt angle and orientation for solar energy collection based on measured solar radiance data. International Journal of Photoenergy, Vol. 2007, Article ID 85402, 9 pages. doi:10.1155/2007/85402.

[26] SAURAN, 2015. Southern African Universities Radiometric Network, Solar radiometric data for the public. Available online: http://www.sauran.net/ [Last accessed on 2016/02/23].

[27] Brooks, M.J. et al., 2015. SAURAN: A new resource for solar radiometric data in Southern Africa. Journal of Energy in Southern Africa, Vol. 26(1), pp. 1-10.

[28] Jacovides, C.P., Tymvios, F.S., Assimakopoulos, V.D., Kaltsounides, N.A., 2006. Comparative study of various correlations in estimating hourly diffuse fraction of global solar radiation. Renewable Energy, Vol. 31, pp. 2492-2504.

[29] SunEarthTools, 2015. SunEarthTools.com, Tools for consumers and designers of solar. Available online: http://www.sunearthtools.com/ [Last accessed on 2015/07/10].

[30] Michalsky, J.J., 1988. The Astronomical Almanac's algorithm for approximate solar position (1950-2050). Solar Energy, Vol. 40(3), pp. 227-235.

[31] Kipp \& Zonen, 2011. Instruction Manual: 2-Axis sun tracker, SOLYS 2. Available online: http://www.kippzonen.com/ [Last accessed on 2015/07/10].

[32] Goswami, D.Y., Kreith, F., Kreider, J.F., 2000. Principles of Solar Engineering, $2^{\text {nd }}$ Edition. Philadelphia: Taylor \& Francis.

[33] Pandey, C.K., Katiyar, A.K., 2009. A note on diffuse solar radiation on a tilted surface. Energy, Vol. 34, pp. 1764-1769. 
[34] Gulin, M., Vašak, M., Baotić, M., 2013. Estimation of the global solar irradiance on tilted surfaces. In: Proceeding of the 17th International Conference on Electrical Drives and Power Electronics (EDPE 2013).

[35] Diez-Mediavilla, M., De Miguel, A., Bilbao, J., 2005. Measurement and comparison of diffuse solar irradiance models on inclined surfaces in Valladolid (Spain). Energy Conversion and Management, Vol. 46, pp. 2075-2092.

[36] Stine, B.S., Harrigan, R.W., 1985. Solar Energy Fundamentals and Design. New York: John Wiley \& Sons, Inc.

[37] Ho, C.K., 2008. Software and Codes for Analysis of Concentrating Solar Power Technologies, Sandia Laboratory Report: SAND2008-8053.

[38] GeoSun Africa, 2015. Updated satellite maps of South Africa's solar resource. Available online: http://www.sauran.net/ [Last accessed on 2015/07/10].

[39] Zawilska, E., Brooks, M.J., 2011. An assessment of the solar resource for Durban, South Africa. Renewable Energy, Vol. 36, pp. 3433-3438. 